\title{
Forma y transgresión: el discurso del arte
}

\section{Form and transgression: The discourse of Art}

\author{
J. Manuel Álvarez-Junco \\ Universidad Complutense de Madrid \\ bbaajun@ucm.es
}

Recibido: 18 de diciembre de 2014

Aprobado: 10 de marzo de 2015

\section{Resumen}

$\mathrm{El}$ arte, en sus diferentes campos, desarrolla un tipo de discurso que nada tiene que ver con el de otros ámbitos. Se vale de combinaciones de elementos diversos, normalmente pertenecientes a lenguajes convencionales, para elaborar un enunciado único y nuevo, donde una idea encuentra finalmente su forma. El contenido y la estructura se fusionan en un punto indisoluble. En este artículo se plantean las búsquedas de paradigmas clásicos de la forma artística y una reflexión al respecto desde el ámbito de las Artes Visuales. Se parte de la consideración que durante muchos siglos se tenía de la representación o imitación de la realidad no solo como vehículo de la expresión sino como la finalidad del arte. Se continua por el foco que la Transgresión de Dadá estableció en aquellas formas artísticas que buscan una conmoción emocional para que la creación alcance los territorios íntimos del receptor. Por último, se explica el fundamental hallazgo de Duchamp de señalar que es el propio discurso de la obra el que proporciona un nuevo pensamiento al mundo.

Palabras clave: arte, discurso, representación, transgresión, Dadá

Álvarez-Junco, J.M. (2016): Forma y transgresión: el discurso del arte. Arte, Individuo y Sociedad, 28(1) 91-104

\begin{abstract}
Art, in its various fields, developes discourses that nothing have to do with others coming from different realms. It uses various combinations of elements, usually provided by conventional languages, in order to create a new and unique speech, where an idea finally finds its own form. At that precise spot, content and structure become an unique and inseparable one. This paper deals with classical art paradigms and reflects on them, particularly from the Visual Arts point of view. It begins by thinking about many centuries mainstream art forms as reality representation or imitation, not only as a vehicle for expression but as an actual purpose of art itself. It follows with the proposal of Dada transgression to those art forms looking for emotional commotion so that a creation reaches the intimate territories of the receiver's mind. It finally explains how Marcel Duchamp pointed art discourse itself as the one made to give a new thinking to the world. Keywords: art, discourse, representation, transgression, Dada.
\end{abstract}


Sumario: 1. Las formas del orden, 2. La representación como orden, 3. La transgresión como paradigma, 4. La figura de Marcel Duchamp, 5. El discurso del arte, 6. Conclusiones. Referencias.

\section{Las formas del orden}

Es conocido que Stendhal cada día antes de comenzar a escribir leía unas páginas del código civil.

Esta costumbre podría ser calificada como extravagante por quien no haya tenido la curiosidad o la necesidad de adentrarse en un texto de esas características, donde encontraría una redacción sencilla y de una cuidada precisión. Su concreción lingüística y conceptual está destinada a evitar cualquier equívoco en su interpretación. Stendhal disponía de este modo de una gran referencia que le evitaría en sus obras perderse en minucias o curvas estéticas y dejarse de discutibles abstracciones. El motivo principal, expresamente reconocido por el escritor, es, pues, la concisión de sus formas discursivas, fundamentales para una comunicación directa con el lector.

Pero quizás hay alguna otra razón. El código civil (tanto el Code Napoleon de 1804 que usaba Stendhal como el español de Alonso Martínez de 1889, también de extraordinaria calidad) es el contenedor formal de las relaciones privadas, que describe nuestros derechos y obligaciones con los demás, es decir, un cuerpo normativo básico que recoge nuestro orden social. Stendhal tenía ante sí el reflejo de la realidad oficial, el sistema establecido para que la colectividad consultara las normas relativas a las personas, las cosas y los actos con consecuencias legales.

La selección del contenido de este texto por parte de Stendhal no debía ser caprichoso, por tanto, porque estar ante la legislación del derecho civil común se relaciona con el hecho de que para el trabajo de cualquier creador no es aleatorio encarar cada día, para bien o para mal, la intrincada jungla del sistema normativo en que vive. Se podría perfectamente definir esta acción como tener bien presente el gran catálogo de formas de derecho privado, es decir, lo que la colectividad considera el orden.

Los humanos llenamos nuestro mundo con un océano de pautas, elaboradas para valernos mejor en la incertidumbre y contingencia de la vida. Estas reglas, a veces escritas en un código, a veces simples costumbres y usos sociales, surgen en su mayoría del colectivo y por él nos son dispuestas. Siendo esto cierto, también lo es que nosotros mismos, como individuos y miembros del grupo, tenemos necesidad de un sistema de referencias. Todos establecemos por nuestra cuenta, o adquirimos de otros, patrones de actuación de muy variados tipos, de modo que convertimos nuestra vida en un mundo, mejor o peor, pero formalmente reglado. Dividimos, por poner algunos ejemplos, nuestro tiempo en siglos, en años, en horas o incluso en segundos, separamos el saber por materias y niveles, distribuimos el día en retos o rutinas, en trabajos u ocios, establecemos condiciones y compensaciones en nuestro trato con los demás, clasificamos a la gente por edades, géneros, nacionalidades, religiones e ideologías, seleccionamos o apartamos por diversas razones a seres u objetos, designamos actividades preferentes, espacios, momentos, días a destacar, elegimos ropas, comidas, deportes, compañías, etc. De una u otra manera, establecemos en todo momento una jerarquía y una secuencia para nuestros actos, una moral, un método y 
una estructura. Más tarde, sufriremos o aceptaremos, apoyaremos o nos rebelaremos contra lo que nos regula, combatiremos aquello que consideramos que nos ataca, pero nuestras vidas tienen una referencia ordenada.

Después de la lectura del código civil, Stendhal se dispone a usar como modelo de estilo narrativo su rigor y precisión, aprendiendo de la comprensibilidad de su discurso y evitando cualquier juego ambiguo. La total corrección de ese planteamiento lingüístico, sin embargo, y aquí está lo interesante, en absoluto tiene que ver con la extraordinaria novedad de la Forma que, como artista, va a ofrecer su obra. Todo se va a dirigir a elaborar su particular y novedoso juego porque el arte no consiste precisamente en acomodarse a la realidad regulada. Su planteamiento conceptual será superar los límites del pensamiento colectivo. La claridad expresiva contrastará con el espíritu innovador que pretende elevar el entorno social a partir de su acción artística. Nada tiene el código civil de la complicidad, ni del guiño, ni del juego, ni de la sorpresa formal que, como creador, se apresta Stendhal a realizar con el discurso del arte.

\section{La representación como orden}

La vida en general supone una lucha contra la entropía, el desorden y el caos, por lo que el hombre necesita un sistema que le proporcione un equilibrio. Este conflicto entre lo particular y lo universal es el que lleva a las personas a la búsqueda de paradigmas para abordar el mundo.

El arte, como actividad fundamental humana, se encuentra en la búsqueda fundamental de ese orden, aunque se puede afirmar que su misión no está dedicada a un rastreo genérico sino a encuentros muy concretos. Rudolf Arnheim explica en su libro Arte y entropía que el orden es una condición necesaria para que algo pueda ofrecer un significado ante los demás (Arnheim, 1980).

El artista, consciente de que su acción se desarrolla en los sistemas diversos que componen nuestro entorno y que su obra se dirige a los demás, busca que su propuesta sea recibida y entendida, lo que significa ser respondida por el colectivo con su aprobación. Ese necesario "feed back" lleva al artista a procurar algo sorprendente pero a la vez comprensible y aceptable.

A la pregunta “¿Qué es el arte?” respondía Tolstoi en 1898 definiéndolo no solo como una estricta comunicación sino sólo válida si las emociones que transmitía podían ser compartidas por los demás seres humanos (Tolstoi, 2007, p. 20). De esta manera señalaba la imperiosa necesidad de una acción cómplice, es decir, de un discurso donde el autor se encontrase con el sentimiento del espectador.

La obra necesitaba previamente ofrecer una lectura coherente, adecuada y siempre nueva para el espectador, pero añadía que el autor no debía conformarse con transmitir o provocar sentimientos sino incluso "contagiarlos": el arte realiza una maniobra de encuentro del autor con el espectador, de comunión con él a través de la forma particular de la obra.

Una referencia primaria que se ofrece para la creación artística es el orden "natural". Es decir, que un sistema de lenguaje que aparece como válido en primera instancia es el que proporciona el registro y transmisión de lo que se percibe del mundo, el reflejo de lo que se considera como realidad. La capacidad de imitar, de 
mimetizar y reproducir, por ello, es una destreza admirada de siempre por el humano. La posibilidad de representación ofrece al artista ante su espectador la demostración del mundo tal y como nos llega. La persona del arte, capturando y comunicando esa forma exterior, aspira a mostrar el mundo a los demás.

Desde la infancia poseemos un impulso imitador que Piaget señala como una unívoca muestra de la inteligencia del individuo. De alguna manera el niño reconoce así un modo y modelo de actuar, una pauta a seguir, la referencia a un sistema de orden. Según Piaget la imitación es un hecho no voluntario, un acto automático, que posteriormente llevará a lo que denominamos aprendizaje. Por medio de la repetición de lo observado el hombre consigue un patrón, la representación de algo que le sirve de modelo para actuar en situaciones similares con idénticas respuestas. Este autor dedica un libro a la imitación (toda la primera parte), el juego y el sueño. (Piaget, 1996).

Desde la antigüedad se ha valorado y reflexionado sobre esa destreza comunicadora cargada de complicidad que proporciona la habilidad imitatoria del hombre -y sabemos hoy que también de algunas otras especies animales- que obtiene una directa y práctica conexión con el grupo. Aristóteles mismo afirmó que "no hay arte sin imitación" señalando que esta habilidad característica diferenciaba a las personas de las bestias, definiendo al hombre como "animal mimético" y destacando que imitar es una fuente de placer para el espectador. Este filósofo, sin embargo, no sugiere con sus comentarios dirigirse a un tipo de fiel reproducción o copia como tal ya que será consciente de que una obra siempre es un "artificio" o "elaboración". La mímesis a que alude consistirá en buscar modelos de referencia para el propósito del artista, añadiendo que es el conjunto de la obra lo que importa, debiendo apreciarse el resultado integral que ofrece su forma. (Aristóteles, 2006).

La idea de la imitación desde sus iniciales defensores ha planteado variadas interpretaciones y reticencias, al resultar dudosa la idea de la existencia de una mirada objetiva o de algo o alguien capaz de reflejar fidedignamente aquello que percibe. Así, desde las primeras teorías al respecto ya se diferenciaba entre la imitación particular que pretende una reproducción o reflejo fiel del referente y aquella imitación universal que permite una interpretación o incluso idealización de la naturaleza.

Platón apunta su razonamiento particular al afirmar que "bien lejos de lo verdadero está el arte imitativo" y en su reflexión considera el nuestro como un mundo de ideas y en absoluto de copias de la apariencia o, como despectivamente denomina a las imitaciones, engaños. En La República, en particular en el Libro X, Platón dedicará varias reflexiones al tema de la mímesis. (Platón, 2005). Tanto Aristóteles como Platón coincidirían en la existencia de la diégesis, donde el autor, en contraposición con la mímesis, es el que establece su lenguaje propio, la expresión particular de su mundo.

A lo largo de los siglos el concepto de imitación se entendió de muy diferente manera, con diversas puntualizaciones y derivaciones pero siempre con la clara idea de que la mímesis era el paradigma del arte, donde la meta a lograr era alguna equivalencia de la realidad o un reflejo fidedigno de ella. La Naturaleza era la guía vital y por tanto maestra del arte (Para Santo Tomás de Aquino "El arte imita a la naturaleza en su operación"), bien estableciendo la visión del mundo "real" o bien 
la del sensible, bien de aquello universal o aquello ideal, se denominase copia, evocación o inspiración.

Desde el Renacimiento el paradigma de la mímesis se dirigió a satisfacer el afán humano por representar no solo apariencias sino conceptos. En todo el arte occidental la búsqueda por conectar la visión propia con la del grupo tomó muy distintos rumbos y estilos pero siempre dentro del sistema de realización figurativa donde se destacaba la dificultad de reflejar la realidad. Este espectáculo aspiraba a la reproducción de lo más externo o superficial ("que casi se pueda tocar") o bien a algo más particular: la plasmación o encarnación de los aspectos más íntimos e invisibles ("que casi se pueda sentir"), lo que incluía la representación de lo imaginario.

El Manierismo dejó claro que el artista no pretendía expresar el mundo sino "su" mundo, incluyendo lo fantástico y lo grotesco. Mediante la minuciosa simulación de lo real, el Barroco procuró una participación del espectador centrada en lo emocional ofreciendo como pretexto escenas alegóricas de la cultura clásica y temas mitológicos.

La complicidad que ofrecía una y otra vez ese paradigma se centraba en la fascinación por ofrecer supuestamente el mundo como "lo vemos", la conquista de las formas aparentes. De esta manera, un espejo cuya imagen estaba realizada "a mano" obtendría la identificación y señalamiento de su autor como uno de los nuestros, capaz de mostrar "lo evidente" ante el grupo. La meta de hallar el reflejo que mostrara la realidad, el hallazgo de la forma que consiguiera visualizar la vida, es imposible, según el filósofo Nelson Goodman desde un punto de vista estructuralista, ante la absurda quimera de la existencia de un "ojo inocente" ya que cada representación posee sus códigos concretos (Goodman, 2010).

En el siglo XVIII el principio de verosimilitud, es decir, la sustitución de la realidad, comienza a ser superado por el de creatividad, siempre dentro del incuestionable paradigma figurativo. Al artista se le comienza a considerar entonces como alguien que aporta algo nuevo y no copia de lo que ve, es decir, un creador. Kant, en su Crítica del Juicio considera al artista como alguien donde imaginación y entendimiento se encuentran y coinciden. (Kant, 1999).

A lo largo del siglo XIX diversas escuelas y artistas individuales desarrollan variados sistemas de figuración; pero a mediados del siglo comenzó a parecer que las opciones se estaban agotando. Los Románticos, los Prerrafaelistas y los distintos grupos Historicistas consiguieron reavivar, durante un limitado período, hermosas formas y temas pasados. El Realismo aportó una llamada al mayor reflejo de la vida, el trato de temas más terrenales y menos personales, con un mayor contacto con la cotidianeidad y sus problemas.

Nada ajeno a esta crisis del XIX era el hecho de que la fotografía había arribado para sembrar una importante incertidumbre sobre el imperio de la representación como sistema formal artístico. Si lo que se deseaba era reflejar la apariencia, si lo que se buscaba era obtener la concreción de la imagen real, y eso solo se erigía en pretensión fundamental, la máquina fotográfica era capaz de realizar una figuración de manera más precisa que la pintura. Hoy nos puede sorprender que la fotografía fuera presentada a mediados del siglo XIX ante la Royal Society de Londres como una "máquina de autodibujo". Tanto Daguerre, que era un artista, como Niépce y Talbot, plantearon su invento como una herramienta para sustituir la mano del hombre en la representación de la realidad. Este increíble invento, que retrataba fielmente 
la realidad según las leyes de la óptica, que conseguía una objetivación del mundo visible, imponía la reubicación de esa difícilmente cuestionable función artística, la meramente figurativa, al relativizar su importancia. Desde entonces la finalidad de la obra de arte no sería ya más la sola exhibición de la capacidad artesanal de reproducir las formas exteriores. A partir de la fotografía la esencia del arte no estaría en su coincidencia con la representación sino que habría que buscarla en otro lugar.

Un último y excepcional movimiento de fin del XIX, el Impresionismo, llevó la complicidad en figuración a extremos de intensidad, realizando una particular y fluida interpretación de las formas externas, con predilección por el tema paisajístico. Nada de esto parecía suficiente, sin embargo, porque el siglo XX precisaba encontrar para esa deseable comunión artista-mundo un nuevo paradigma que les sacara del estancamiento al que había conducido la corrección en la representación.

La salida surgió inopinadamente con la aparición de un tremendo desafío al arte según se había entendido hasta entonces, algo que se puede denominar bajo el título de La Transgresión.

\section{La transgresión como paradigma}

Transgredir (Del latín trans -más allá- y el verbo gradior -pasar para acceder a otro lado-), es sobrepasar los límites del orden, no seguir las pautas aceptadas, saltarse los patrones establecidos. Por tanto, la transgresión supone una quiebra del sistema aceptado, una superación del mismo.

Ya se ha hablado de que una colectividad sólidamente establecida se apoya en el orden social, para cuyo mantenimiento es esencial que sus individuos hagan suyos un conjunto de usos y formas de comportamiento que consideran "reales" y "objetivos", aquello que Alfred Schutz llama "la realidad predominante de la vida cotidiana" (Schutz, 1962). Cualquier sistema que nos rija, sin embargo, resulta insatisfactorio para el individuo, y a la vez la vulneración de sus límites puede resultar peligrosa para una sociedad que necesita ese orden. El dilema entre transgredir considerado como violación o como necesaria superación de barreras para progresar no es en absoluto una novedad para el hombre: el mito de Prometeo, el que robó el fuego de los dioses para que los mortales pudieran utilizarlo, el gran transgresor por el bien de los humanos, sigue siendo la referencia clásica.

El hombre, en esa aparente contradicción, se plantea simultáneamente poner un necesario orden a su propio pensamiento y dejar la posibilidad de desconcertar los límites impuestos, aquello que ha sido establecido para proteger sus formas y normas. Existen varios métodos de los que se valen las personas para dejar en evidencia que aunque su sistema por un lado sea un práctico conjunto de normas en absoluto es un orden inmutable y de ningún modo, la verdad.

La acción artística es uno de esos recursos balsámicos ya que proporciona una salida para defenderse de esa presión social, para desvelar el entramado de artificios del Orden al superar las formas establecidas mediante la creación de aquello que antes no existía proporcionando una nueva Forma.

Pareyson, en su teoría de la Formatividad, explica que el arte, a la vez que hace, inventa un modo de hacer. Por tanto una obra artística es un auténtico logro en sí, donde ella misma ha encontrado la regla que la define específicamente al descubrir su propio 
y único camino. Este filósofo señala y destaca la forma artística, diferenciándola de las demás producciones del hombre, al ser donde este actúa únicamente con la estricta finalidad de "formar", que realiza "para formar", es decir, que es "formatividad pura" mientras las demás actividades no tienen esa exclusiva meta. (Pareyson, 1988).

Una exigencia prioritaria del arte es llamar y conseguir acceder al interior de los demás, saltando las barreras que la colectividad y esquivar los controles erigidos para defendernos de lo aleatorio. Obviamente, si lo que el arte propone estuviera dentro de la normalidad no tendría nada de especial y poco pretendería conquistar, de lo que se deduce que el impacto que causa, la conmoción o la sorpresa, es una característica suya. "Las transgresiones son la mejor y la peor manera de infringir la ley, lo que tal vez pueda resumirse de la siguiente manera: las transgresiones son atropellos capaces de liberar" (Anthony, 2003, p.17). En el mundo del arte, lo distinto, lo transgresor, se convierte en consustancial ya que la acción creadora siempre supone un cuestionamiento de lo obtenido, para así poder alcanzar otro territorio: el hombre no puede quedarse en un punto concreto y debe avanzar, superar el orden cotidiano y pisar espacios de libertad. Esto provocará en nosotros una beneficiosa perturbación por la que se nos permite acceder a nuestros auténticos territorios, descubrir algo que reconocemos íntimamente nuestro, aquello que "es" nosotros mismos. "El arte tiene la obligación de impactarnos de una manera que nos permita descubrir una verdad sobre nosotros mismos, o sobre el mundo, sobre el propio arte; la manera de conseguirlo es alejándonos de nuestras ideas preconcebidas, y haciendo que lo familiar se vuelva extraño y lo que no se cuestiona, problemático". (Anthony, 2003, p. 26,).

Hugo Ball, fundador del Cabaret Voltaire, cuna del Dadaísmo, señala el impactante efecto del arte, es decir, la conmoción emocional que provoca, como el mecanismo de apertura, como el golpe capaz de hacernos abrir los ojos, para el que el arte es "la ocasión y el método". Este movimiento pretenderá "una búsqueda ardiente, cada día más flagrante, del ritmo específico, del rostro soterrado de esta época. De su fundamento y esencia; de la posibilidad de conmoverla, de despertarla" (Anders, 2005, p.12).

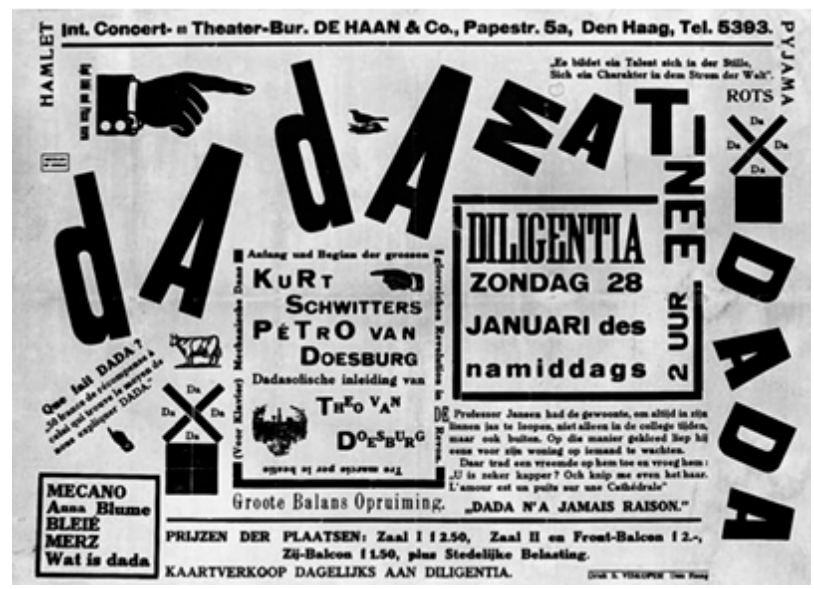

Figura 1. Cartel de Theo Van Doesburg anunciando la matinée de presentación de Dadá en Zurich, 1916. Foto: Centraal Museum Utrecht. 
Desde el primer momento los dadaístas plantean la idea radical de lo transgresor como forma creadora en sí. No hay concesiones ni reparos en esa búsqueda de los resquicios que consigan convulsionar el mundo y así hacerlo salir de su atolladero. Dadá aborda un brutal y demoledor desafío al arte instituido, renegando de la solemnidad y el alejamiento de la vida cotidiana a la que había llegado. Denuncia la crisis del pensamiento burgués y su ideal "moderno" del progreso humano, y plantea que el artista, para "devenir serio", debe olvidar la neutralidad y guiarse por la violación de la norma. La única misión del arte será, para ellos, su auto-disolución, su propio desguace, su desaparición. La transgresión se erige en sistema con la radical determinación de reunir lo cuidadosamente marginado, adorar lo banal, ridiculizar lo sagrado, desmontar lo obvio y celebrar el absurdo. El escándalo se convertirá en útil artístico y valdrá más el gesto que la obra en sí, siempre que ese gesto sirva como acto contra el sentido común y contra cualquier tipo de ortodoxia, que desmonte el sentido común, la moral, la norma, la forma. Una idea de Tristan Tzara era unir el Viernes Santo con el Carnaval: "Lo que celebramos es una bufonada y una misa de difuntos a un tiempo". (Ball, 2005, p. 113). En el primer Manifiesto Dadaísta, escrito por Tzara y publicado en 1918 en la Revista DADA de Zurich, se dice: "afortunadamente no todas las flores son sagradas y lo que es divino dentro de nosotros es el despertar de la acción antihumana" (Tzara, 1992, p. 209).

La imitación como motor de la representación es denunciada como el paradigma responsable que había conducido, según Dadá, a "la nada inflada". Ahora, en cambio, es el sobresalto el que se presenta como la solución que da acceso al pensamiento. "La obligación del arte es devenir "serio" y, tomando su revancha, romper el continuum de diversión de lo cotidiano para desacreditarlo. A una vida radiante, un arte infernal." (Anders, 2005, p.13).

Consciente de que aquello nuevo y desconocido, lo inesperado e inconveniente, que crea incertidumbre y expectación, atraen al realizar lo que la "normalidad" o la "corrección" más temen a la vez que secretamente desean, Dadá se lanzará a la exaltación de la rebeldía y la incorrección, el absurdo y el escándalo, la locura o la imbecilidad, cualquier radicalidad que consiga echar abajo las limitaciones del orden. "En el propio hombre se encuentra la palanca para sacar de quicio este mundo nuestro agotado" (Ball, 2005, p. 151). 


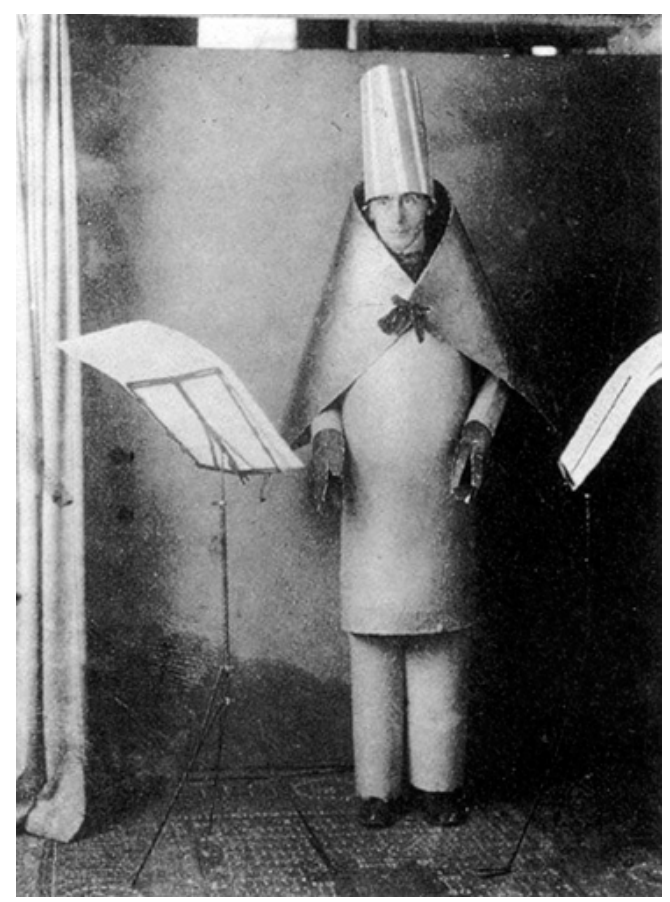

Figura 2. Hugo Ball presentado el sonido-poema "Elefentenkarawane".

Fotografiado en 1916 en el Cabaret Voltaire. Foto: zoolander52.tripod.com

La "conmoción" sirve para desvelar los huecos del pensamiento, el shock que perturba la normalidad nos regala la aparición de lo que desconocíamos que buscábamos. El arte, mediante la transgresión y desvirtuación de las tramas formales, consigue desvelar su artificiosidad obteniendo el botín de la sorpresa, de la superación de lo esperado. La provocación y la profanación fuerza a un replanteamiento de lo formal, a una revisión radical del modo de pensar. "Yo destruyo los cajones del cerebro y de la organización social: desmoralizar por todas partes, lanzar la mano del cielo al infierno, los ojos del infierno al cielo, volver a erigir en los poderes reales y en la fantasía de cada individuo la rueda fecunda de un circo universal." (Tzara, 1992, p. 94).

Tristan Tzara realiza una llamada a "desmoralizar" o arrancar de cuajo una moral y conducirla al vacío para alojar al hombre en el experimentalismo vital, como en una "rueda fecunda" en la que los contrarios se prueben. A partir de aquí el paradigma será la provocación, la profanación, la impertinencia, la heterodoxia, la rebeldía, el nihilismo, la revolución,... en fin, lo transgresor elevado a esencia del arte.

\section{La figura de Marcel Duchamp}

No toda incorrección, sin embargo, bastaba para el arte, ya que era preciso que estuviera acompañada de unas particulares condiciones. Pronto comprendieron los Dadaístas que la acción artística exige conducir no a una mera negación o 
contradicción porque la mente precisa de la oferta de un nuevo pensamiento. El juego que reclama es, si se observa bien, una reubicación elemental, donde la acción creadora desarma, enfrenta, cambia, mezcla, acumula, reduce y, en fin, combina el conjunto de ingredientes previos en una nueva construcción significativa. Además, ese gusto por lo paradójico, por lo nunca visto, no puede llegar acompañado de una imposición, no puede significar el forzar la puerta de nadie, porque es imperativo evitar tanto la indiferencia como el rechazo del espectador, cuya participación es imprescindible. Álvarez-Junco (2009) nos dice a este respecto que una transgresión significativa debe siempre ir acompañada por la complicidad ya que si no, no será aceptada por el receptor.

Como antes se ha dicho, la complicidad es un elemento innegociable para obtener la recepción colaborativa del público. La propuesta del arte es siempre compartir un juego, donde la búsqueda de lo insólito debe llevar al ludismo de la incorrección. "Los rasgos de sentido lúdico aparecen sistemáticamente en todos los trabajos sobre personalidad creadora" (Romo, 2007, p. 22). El receptor sabe -el artista sabe, el hombre sabe- que cualquier juego supone una simulación, algo limitado en sus efectos, donde lo ilusorio se comparte pero tiene un final asegurado, una salida por la que se regresa a la vida cotidiana. Coleridge denominó a este mecanismo que activamos con el juego "una suspensión voluntaria de la incredulidad". Esta necesaria aceptación del reto lúdico por parte del espectador, pone en evidencia que el deseo del artista nunca es enfrentarse con la realidad, ni romper seriamente con sus formas sino directamente jugar -aunque sea de forma radical y sin contemplaciones- con ellas.

Marcel Duchamp, dentro de Dadá, decide adentrarse en esta cuestión y será clave para esclarecerla demostrando con sus acciones artísticas que la transgresión por la transgresión no vale y que la sacudida emocional debe ser acompañada por un juego significativo; es decir, es algo que debe provocar en nosotros no una simple conmoción vital sino una reflexión.

Habiendo comenzado como un artista más dentro de los movimientos de su generación de entre-siglos Duchamp a pocos años de iniciar su trayectoria se sumerge en una reflexión sobre el propio mecanismo creador. Su búsqueda se centra en una "pintura que hable solo de sí misma (...), aparte del realismo absoluto, (...) no tributaria de las escuelas existentes (...): una pintura de la idea" (Vicente, 2014, p.1).

$\mathrm{Su}$ revelación parece que se produjo ante una exposición de material aeronáutico, donde encontró una hélice que le hizo exclamar "La pintura ha muerto. ¿Quién podrá crear algo mejor que esta hélice?". En 1913 reformula el concepto de arte: "¿Puede uno hacer obras que no sean de arte”? (Tomkins, 1996, p. 148). Presenta a continuación una rueda de bicicleta sobre un soporte de exposiciones. Sería su primer "ready-made u object trouvé". Duchamp había elegido un objeto cotidiano, que mediante el sorprendente juego realizado por su sencillo señalamiento y una mínima intervención se convertía en arte. ¿La representación qué importaba allí?

Este artista, al que André Bretón consideró "el hombre más inteligente de su época", se disponía a corregir el habitual error de considerar base del arte la función instrumental de la representación. El papel de la figuración, según él, pertenecía a otro nivel mientras la auténtica clave era el juego elemental, el lenguaje en sí, la 
concreta forma ofrecida. Ni la figura, ni el tema, ni la idea ni el contenido propuestos sino la novedad concreta que daba el discurso al espectador era el que proporcionaba el efecto emocional.

Duchamp planta así batalla al paradigma mimético o imitativo, cuestionando la representación como fin, alejándose radicalmente de lo que llama el arte "retiniano" (el que está estrictamente dirigido a la vista) y decidiendo seguir el camino del "arte mental", es decir, el dirigido al pensamiento, a la idea, al concepto. Considera una quimera concretar cuál es la naturaleza artística y decide proponer objetos "neutros" o "indiferentes", no atractivos visualmente, declarándolos arte. Por medio de sus readymade (el urinario asentado horizontalmente, titulado "Fuente", Fig. 3, es un excelente ejemplo) demuestra que no tiene importancia el origen, función o carácter del objeto -y muy poco su representación- que se ofrece como arte; basta con una designación y además -atención- con una significativa manipulación para distinguirlo como tal.

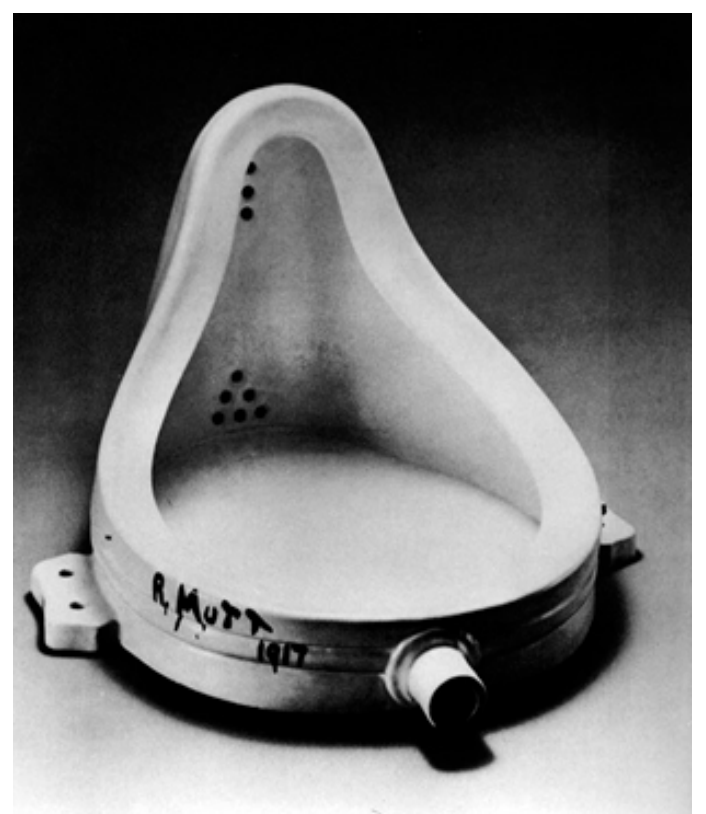

Figura 3. "Fuente", Marcel Duchamp, 1917 (réplica de 1964). Foto: foroalfa.org

Reconoce expresamente que elegir uno u otro objeto al azar es una decisión personal y no sirve lo aleatorio. Esa selección del objeto es, dice, "un juegecito entre mi y yo" (Tomkins, 1996, p. 179).

La fundamental aportación de Duchamp fue señalar que un objeto, figura o no, se transforma en una obra de arte al provocar un pensamiento nuevo para él. Así se decía que Picasso miraba hacia atrás mientras Duchamp hacia delante, al haber mostrado que la obra en absoluto era aquello que representaba, sino que era el mismo objeto en sí, ahora re-nacido como arte, el que realizaba el juego.

A partir de Duchamp, por tanto, será arte aquello que conduce a un descubrimiento personal, a un juego innovador. El tema, el contenido, la figura no tendrá importancia 
sino por lo insólito y sorprendente de la nueva forma. Ella era en definitiva la portadora del juego concreto con el espectador: el discurso.

\section{El discurso del arte}

Desde Duchamp se concluye que las formas no son en absoluto la "hechura exterior de una cosa", como la mímesis perseguía, sino aquello estructurado por el pensamiento, que constituye algo en su esencia. Es decir, la Forma incluye no sólo lo percibido por los sentidos sino el concreto modo de la propia realización.

El arte es un lenguaje abstracto, aunque un tanto particular porque estando la mayoría de los lenguajes compuestos de signos organizados en una estructura que les ofrece un determinado juego combinatorio, el artístico, siéndolo también, en absoluto pertenece a los sistemas de comunicación convencionales.

El del arte no es en principio un lenguaje natural, es decir, no ofrece en absoluto un idioma o un sistema de comunicación más o menos espontáneo o inconsciente, como podría ser una lengua étnica, aunque estas estén compuestas por convenciones o acuerdos de grupo que evidentemente responden a un determinado código. Mucho menos es el arte un lenguaje artificial, elaborado para resolver una necesidad, como la señalética o los códigos científicos.

El arte es en realidad una estructura expresiva que está por encima de esos niveles lingüísticos, de los cuales se vale como material para sus construcciones. En las obras de pintura o de música, aunque se utilicen convenciones (símbolos o temas) para su finalidad, su uso nada tiene de habitual. La poesía y otras artes como la novela, el teatro o el cine se sirven de un idioma convencional para una creación absolutamente fuera de la convención. El lenguaje artístico posee una complejidad en su forma que le permite transmitir un volumen de información superior que el del lenguaje natural y además con mayor simplicidad. El arte, por tanto, no es en absoluto un sistema lingüístico normal, porque, utilizando un lenguaje conocido, cada una de sus creaciones ofrecen un discurso concreto e irrepetible, el descubrimiento de una novedosa forma realizada con otras ya conocidas, donde ha encontrado un sorprendente y rico atajo mental.

La forma artística encontrada se convierte en algo tan fundamental que el contenido abstracto desaparece sin ella. La disposición del lenguaje que ofrece es precisamente lo que le hace existir; la manera que adopta, aquella con la que se muestra, es la que le hace ser. La conclusión obvia es que una idea no es tal hasta que encuentra su forma y, por tanto, contenido y configuración en arte se han vuelto indivisibles. El significado final será, pues, inseparable de sus elementos.

La esencia del arte es la emoción y no solamente la idea o el tema que transporta. Es decir, la forma no es un mero vehículo transmisor sino el propio objeto de la emoción. El discurso es su propio mensaje: solo en la forma existe el contenido. Para Luis Borobio el significado de cada pieza artística es exactamente aquello concreto que dice, sin más (Borobio, 2008). Considérese la enorme falta de interés que supone estudiar el tema o el contenido de una obra de arte, mientras estudiar su discurso es muy provechoso. El arte, en fin, ofrece un discurso donde el creador ha conseguido resolver la complejidad formal inmersa en la complejidad del concepto. La manera en que se utiliza el lenguaje en esa forma única es lo que le hace existir, 
la disposición de sus elementos la que le hace ser. Tolstoi señala "lo absurdo que es buscar ideas aisladas en una obra de arte" y no percatarse de "el infinito laberinto de concatenaciones que constituyen la esencia del arte y las leyes que forman la base de esas concatenaciones" (Tolstoi 2007, p. 38). Ninguna idea artística puede ser tal hasta que no encuentre cómo ser expresada. Ben Shann definía el término configuración como la forma visible del contenido - "Form is the visible shape of content"-, realizando así la fusión de pensamiento y acción. (Shanh, 1957).

El discurso se vuelve, pues, el centro del arte, al ser donde estructura y contenido obtienen su comunión, donde la idea es impensable sin su forma, donde se establece el pensamiento, donde la pieza ha encontrado el significado.

Por tanto, esa afirmación de que "todo está hecho, todo se ha dicho, todo está inventado" se muestra falsa porque todo está por decir y por hacer, desde el momento en que una nueva forma ofrece siempre algo distinto. (Un claro ejemplo de esto es la poesía. Su contenido, separado de su forma, como ocurre en una traducción, la desvirtúa absolutamente. El mérito de una buena versión en otro idioma se debe adjudicar absolutamente al traductor, al haber obtenido una nueva creación a partir de la original, nunca equivalente a ella).

\section{Conclusiones}

Una de las aportaciones de Dadá fue señalar el enorme error que había sido elevar la representación a piedra angular del arte, convertir la imagen imitativa en paradigma. Sus acciones probaron que el papel de la figuración pertenecía a un nivel menos importante, como es el instrumental. Si la esencia del arte no era lo representacional, por mucho valor añadido que aportase, Dadá apuntó a que la clave de todo era una nueva forma, es decir, aquella que superaba lo anterior.

La transgresión que se proponía, sin embargo, no bastaba para conseguir esa emoción que llamamos arte. Sí lo hacía la sacudida proveniente de hallar el punto de encuentro del contenido con su forma, es decir, el significativo y exacto juego del discurso del artista, como se encargó de descubrir Marcel Duchamp. Este aportó la novedad del pensamiento que ese hallazgo formal, sea figura o no, abre sobre un objeto.

Si la representación quedaba definitivamente colapsada como paradigma, gracias a Duchamp la transgresión se concreta, al elevar a categoría creativa, por medio de los "ready-made", la designación y mínima manipulación del artista de cualquier objeto al paso. Se iniciaba así lo que después será el arte conceptual, "el arte sin soporte".

La forma que desarrolla el discurso de cada obra, es para el arte algo tan crucial, que sin duda se puede afirmar que el resto pierde importancia. Forma y contenido son inseparables, ya que la información proporcionada por una obra artística ha arribado a un punto de transmisión único e inaccesible de otra manera; nada resulta casual allí donde, como en un organismo vivo, la vida resulta inseparable de su cuerpo físico.

El juego concreto establecido con el lenguaje en sí es lo que confiere la categoría de arte a una idea. Su discurso es su mensaje. El tema, el contenido, la idea, ya no tendrá importancia sino por lo sorprendente de su significativa configuración. Aquello que nos lleva a esa forma concreta antes nunca vista es, en definitiva, lo que llamamos arte. 


\section{Referencias}

Álvarez-Junco, M. (2009). El Diseño de lo Incorrecto. Buenos Aires: La Crujía.

Anders, G. (2005). George Grosz: arte revolucionario y arte de vanguardia. Vigo: Maldoror.

Anthony, J. (2003). Transgresiones, el arte como provocación. Barcelona: Destino.

Aristóteles. (2006). Poética. Madrid: Alianza editorial.

Arnheim R. (1980). Hacia una psicología del arte: arte y entropía. Madrid: Alianza editorial.

Ball, H. (2005). La huida del tiempo (un diario). Barcelona: Acantilado.

Borobio, L. (2008). Forma y contenido del arte. Pamplona: Universidad de Navarra. Calabrese, O. (1987). El lenguaje del arte. Barcelona: Paidós.

Goodman, N. (2010). Los lenguajes del arte. Aproximación a la teoría de los signos. Barcelona: Paidós.

Kant, I. (1999). Crítica del juicio. Madrid: Espasa Calpe.

Lotman, Y. (1982). El arte como lenguaje. Estructura del texto artístico. Madrid: Istmo.

Marote, D. (2007). Dadá y la crítica de la cultura. Una poética de la transgresión. Thémata, Revista de Filosofia, $n^{\circ} 39$. Valencia: Univ. de Valencia.

Pareyson, L. (1988) Conversaciones de Estética. Madrid: La balsa de la Medusa.

Piaget, J. (1996). La Formación del Símbolo en el Niño. México: Fondo de Cultura.

Platón (2005). La República. Madrid: Alianza editorial.

Romo, M. (2007). Juego y creatividad en el niño. En Hernández-Belver y Ullán eds., La creatividad a través del juego. Salamanca: Amarú,

Shanh, B. (1957). The shape of content. Cambridge: Harvard University Press.

Schutz, A. (1962). On multiple realities. Collected Papers, La Haya: Nijhoff.

Tzara, T. (1992). Manifiesto Dadá, 1918. En R. Huelsenbeck (ed.), Almanaque Dadá. Madrid: Técnos.

Tzara, T. (1999). Siete manifiestos Dadá. Barcelona: Tusquets Editores.

Tolstoi, L. (2007). ¿Qué es el arte?. EUNSA, Pamplona: Ed. Univ. de Navarra.

Tomkins, C. (2013). Duchamp. Madrid: Anagrama.

Vicente, A. (2014). Duchamp antes del urinario. Diario El País. Crónica 24 septiembre de 2014 en Madrid. 